\title{
Case Report: Transorbital approach for the management of an orbito-temporal penetrating brain injury (skull base
} region) secondary to wooden spikes [version 1; peer review: 2

\section{approved with reservations]}

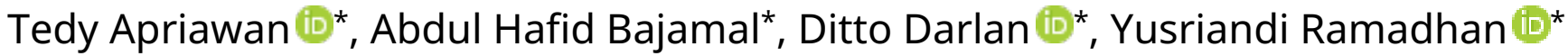 \\ Department of Neurosurgery, Universitas Airlangga, Faculty of Medicine, Dr. Soetomo Academic General Hospital, Surabaya, East \\ Java, 60285, Indonesia \\ * Equal contributors
}

V1 First published: 15 Dec 2021, 10:1283

https://doi.org/10.12688/f1000research.74382.1

Latest published: $15 \mathrm{Dec} 2021, \mathbf{1 0 : 1 2 8 3}$

https://doi.org/10.12688/f1000research.74382.1

\section{Abstract}

Background and importance: Transorbital penetrating brain injury (PBI) due to a non-projectile foreign body is rare. It can lead to lifethreatening severe neurovascular damage. Surgery is the primary treatment choice; however, there are a number of approaches that can be considered based on the patient's condition in terms of foreign body location and state of the patient.

Clinical presentation: An 18-year-old male carpenter was hit by a log and sustained transorbital PBI while cutting wood with a machine. Computed tomography (CT) scan showed a wooden spike that was approximately $11 \mathrm{~cm}$ from the left medial orbital to the superior part of the posterolateral of the petrous bone, crossing the right side at the base of the skull. CT angiography (CTA), magnetic resonance angiography (MRA), and magnetic resonance venography (MRV) revealed no internal carotid artery (ICA) and cavernous sinus lesions, respectively. We had a 3D-printed model for preoperative planning, and surgery was performed using a transorbital approach to extract the wood 14 days after the accident. The impacted wood was removed without any complications.

Conclusion: There are many surgical approaches for transorbital PBI. We decided to perform the transorbital approach because it is perpendicular to the entry zone. Surgeons should consistently perform minimally invasive procedures based on the clinical and radiological findings.

\section{Keywords}

penetrating brain injury, PBI surgical management, transorbital approach wooden foreign body

\section{Open Peer Review}

\begin{tabular}{ccc} 
Approval Status & $?$ \\
& 1 & 2 \\
\hdashline & $?$ & $?$ \\
version 1 & view & view \\
15 Dec 2021 & $\ldots$
\end{tabular}

1. Mamoru Murakami, Kyoto Tanabe Central Hospital, Kyoto, Japan

2. Chi Hoon Choi, Chungbuk National

University Hospital, Cheongju, South Korea Any reports and responses or comments on the article can be found at the end of the article. 
Corresponding author: Tedy Apriawan (drtedyapri@fk.unair.ac.id)

Author roles: Apriawan T: Conceptualization, Data Curation, Investigation, Methodology, Validation, Visualization, Writing - Original Draft Preparation, Writing - Review \& Editing; Hafid Bajamal A: Conceptualization, Data Curation, Methodology, Writing - Original Draft Preparation, Writing - Review \& Editing; Darlan D: Conceptualization, Investigation, Methodology, Validation, Visualization, Writing Original Draft Preparation, Writing - Review \& Editing; Ramadhan Y: Conceptualization, Investigation, Methodology, Visualization, Writing - Original Draft Preparation, Writing - Review \& Editing

Competing interests: No competing interests were disclosed.

Grant information: The author(s) declared that no grants were involved in supporting this work.

Copyright: @ 2021 Apriawan T et al. This is an open access article distributed under the terms of the Creative Commons Attribution License, which permits unrestricted use, distribution, and reproduction in any medium, provided the original work is properly cited.

How to cite this article: Apriawan T, Hafid Bajamal A, Darlan D and Ramadhan Y. Case Report: Transorbital approach for the management of an orbito-temporal penetrating brain injury (skull base region) secondary to wooden spikes [version 1; peer review: 2 approved with reservations] F1000Research 2021, 10:1283 https://doi.org/10.12688/f1000research.74382.1

First published: 15 Dec 2021, 10:1283 https://doi.org/10.12688/f1000research.74382.1 


\section{Background and importance}

Transorbital penetrating brain injury (PBI) secondary to a non-projectile foreign body is rare and potentially lifethreatening. The orbital wall is thin; therefore, access to the cranial cavity through this region can be swift. It can cause severe damage to the eye, optic nerves, brain parenchyma, and neurovascular structures. ${ }^{1}$ Prevalence studies have reported that transorbital PBI accounts for $45 \%$ and $24 \%$ of all traumatic brain injury in children and adults, respectively, and accounts for $0.04 \%$ of all traumatic brain injury and $4.5 \%$ of all orbital pathologies. ${ }^{2,3}$

Transorbital PBI at the skull base region can cause severe neurovascular damage. Vital structures, such as cranial nerves, arteries, and the cavernous sinus, are of particular concern during preoperative planning for surgery in patients with transorbital PBI in the skull base region. ${ }^{4}$ Immediate complications (that can occur within a week of injury) include haemorrhage, vascular damage (such as carotid-cavernous fistula [CCF], traumatic aneurysm, and intravascular thrombosis), ischemic brain injury, brain oedema, and cerebral contusion. ${ }^{5}$ Delayed complications (that can occur after more than a week of injury) include infections (meningitis, encephalitis, and orbital cellulitis), foreign body migration, hydrocephalus, and cerebrospinal fluid (CSF) leakage. ${ }^{5}$ Therefore, it is essential to understand the mechanism of injury, reconstruction of preoperative planning surgery, and postoperative care. ${ }^{4}$ The timing of surgery also needs to be considered in patients with a wooden transorbital PBI, especially when it involves a rough wooden surface, as it can cause more severe tissue damage. ${ }^{4}$ Adequate debridement, administration of antibiotics, and anti-seizure prophylaxis are also required to achieve a satisfactory outcome. ${ }^{6}$

Surgery is the primary treatment for most cases of transorbital PBI. Available approaches include the transorbital approach, right or left frontal craniotomy applying the subfrontal approach, right or left frontotemporal craniotomy, bifrontal craniotomy using the anterior interhemispheric approach, lobectomy, and the percutaneous lumbar intrathecal approach. ${ }^{7-12}$ In our case, we considered using the transorbital approach in view of the clinical and radiological features that are associated with such cases of wooden transorbital PBI.

\section{Clinical presentation}

An 18-year-old male carpenter sustained a wooden PBI at two locations- the right frontoparietal and left orbito-temporal areas, and the base of the skull — while cutting wood with a machine. The wood in the frontoparietal area was extracted, and bone decompression along with evisceration of his left eye were performed six hours after the incident at the district general hospital. Afterwards, the patient was referred to our hospital for further management. He complained of pain and loss of sight in the left eye. He had a Glasgow Coma Scale (GCS) score $\mathrm{E}_{4} \mathrm{~V}_{5} \mathrm{M}_{6}$, trigeminal nerve palsy $\left(\mathrm{V}_{2}\right.$ and $\left.\mathrm{V}_{3}\right)$, facial nerve palsy of the peripheral type (House Brackmenn grade IV) and left-sided hemiparesis. There was no sign of CSF leakage.

Laboratory examinations revealed leucocytosis and increased C-reactive protein (CRP) and procalcitonin levels. Computed tomography (CT), magnetic resonance imaging (MRI), magnetic resonance angiography (MRA), and a 3D-printed model were used preoperatively to plan for surgery (Figure 1). There were no lesions in the internal carotid artery, cavernous sinus, and transverse sinuses (Figure 2). We surgically extracted the wood 14 days after the accident. Empirical antibiotics were administered for six weeks while awaiting definitive antibiotic treatment based on microbiological and antibiotic susceptibility tests. Phenytoin was administered for a week after the accident for post-traumatic seizure prophylaxis.

\section{Surgical procedure}

\begin{tabular}{|l|l|}
\hline Step 1: & $\begin{array}{l}\text { The patient was placed in the supine position, facing the right side. Following surgical draping, the } \\
\text { operating area around his left eye was disinfected. He was placed perpendicular to the operator's view. }\end{array}$ \\
\hline Step 2: & A linear incision was made on the conjunctiva. \\
\hline Step 3: & $\begin{array}{l}\text { The superior and inferior palpebrae were gently retracted using the Langenbeck retractor. Blunt } \\
\text { dissection of the left orbital soft tissue was then performed. }\end{array}$ \\
\hline Step 4: & The tip of the wooden foreign body was identified on the medial orbital wall. \\
\hline Step 5: & $\begin{array}{l}\text { Osteotomy was performed using Kerrison punch forceps until the hole at the penetration area became } \\
\text { wider. }\end{array}$ \\
\hline Step 6: & $\begin{array}{l}\text { The wood was extracted gently using a bone rongeur. Extraction was performed perpendicular to the } \\
\text { operator's view. }\end{array}$ \\
\hline Step 7: & $\begin{array}{l}\text { Haemorrhage was evaluated and treated after extracting the wood. Further haemostasis was achieved } \\
\text { using Gelfoam and Surgicel. }\end{array}$ \\
\hline Step 8: & \begin{tabular}{l} 
Suturing in layers and canthorrhaphy were performed (Figure 3). \\
\hline
\end{tabular}
\end{tabular}




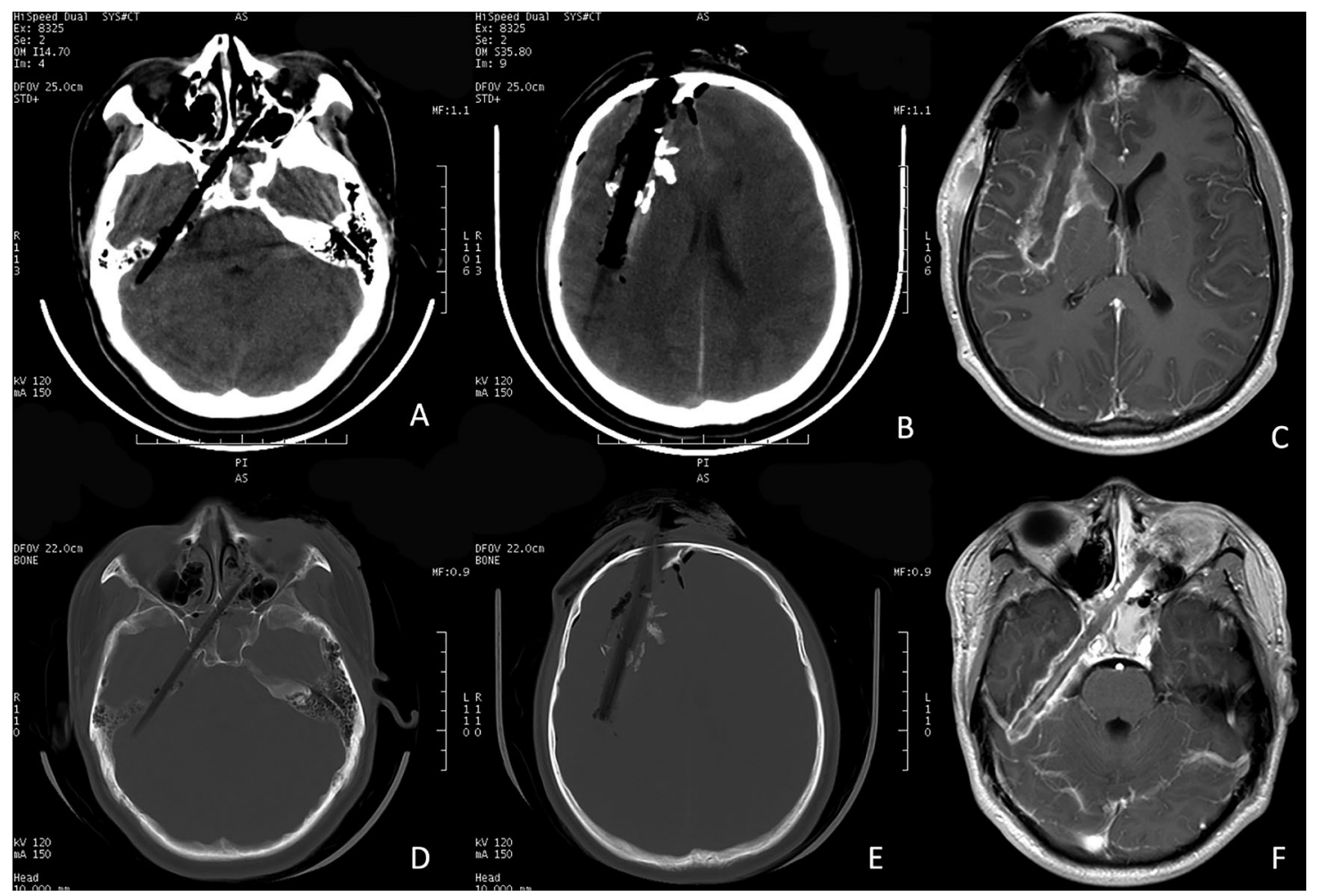

Figure 1. Brain computed tomography (CT) scan without contrast shows a piece of wood about $11 \mathrm{~cm}$ (with a low signal density on CT scan). (A) The wood is seen to extend from the left medial orbital region, ethmoid sinus, across the contralateral sphenoid sinus, and reach the superior part of the posterolateral surface of the petrous bone before crossing to the right side. (B) Another piece of wood that extends from the right frontal to the right parietal region (about $10 \mathrm{~cm}$ long) is also observed. (D) and (E) show bone window segments. (C) and (F) T1-weighted contrast magnetic resonance imaging (MRI) using gadolinium shows that the foreign body had formed a fibrous capsule.

\section{Postoperative follow-up}

Postoperative CT scan evaluation revealed gross total extraction without any haemorrhagic lesion along with a GCS of $\mathrm{E}_{4} \mathrm{~V}_{5} \mathrm{M}_{6}$ (Figure 4). The patient was discharged six weeks after the pieces of wood were extracted, and no apparent clinical complications and abnormal infectious parameters (leucocyte, CRP, and procalcitonin) were found. Six months postoperatively, there was no feature of trigeminal nor facial palsy. The patient could return to his usual activities, and a customized ocular prosthesis was made for his left eye.

\section{Discussion}

The goals of surgery in cases of wooden transorbital PBI include: (1) debridement of non-vital tissues, considering the extensive damage the wood may have caused; (2) evacuation of hematomas, such as extradural, subdural, and intraparenchymal hematoma; (3) removal of as much bone fragments as possible; (4) retrieval of foreign body fragments (larger fragments should be meticulously sought out, as they tend to migrate); (5) securing of adequate haemostasis; and (6) watertight closure of the dura mater, which usually requires the use of grafts. Turbin anatomical criteria refer to zone $3 \mathrm{~b}$ (medial canthus) as the area where the orbital area exits at the superior orbital fissure and sphenoid wing. ${ }^{1}$ The aspects of the central nervous system at risk of damage in that area include the cavernous sinus, temporal lobe, brain stem, or basal cistern. ${ }^{1}$

In our case, the patient underwent a two-stage surgery. The first stage of surgery was debridement, surgical extraction of the right frontoparietal wooden object, bone decompression, and left ocular evisceration, which were done six hours after the incident at the district general hospital. The bone flap removed from the injured side was placed on the contralateral subgaleal layer of the injured side. The patient was referred to our hospital because we were more equipped to manage the extraction of the wood from the orbito-temporal part of the base of the skull. In this case we also performed the 3D-printed reconstruction for the surgery plan because 3D-printed model reconstruction can help neurosurgeons for surgical strategies, and it enhances the anatomical visualization of the location and trajectory of the foreign body, which is not completely visible from the outside (Figure 5). ${ }^{13}$ 


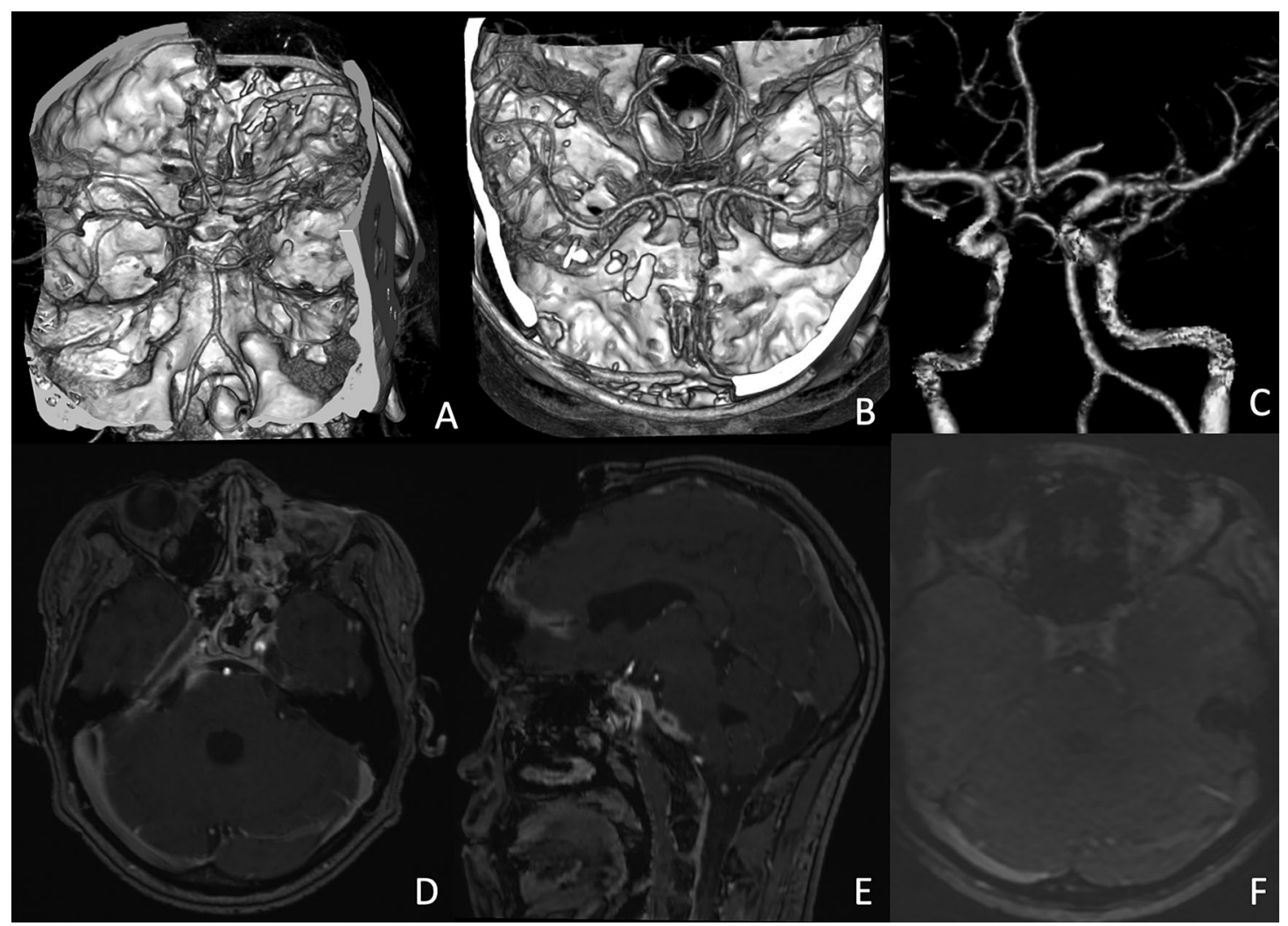

Figure 2. Further radiological evaluation. (A), (B), and (C) computed tomography (CT) angiography and reconstruction of the cerebral arteries shows no rupture in the internal carotid artery (ICA). (D) magnetic resonance angiography (MRA) reveals narrowing of the right ICA that is compressed by the one of the pieces of wood. (E) magnetic resonance venography (MRV) shows no lesion in the cavernous sinus.

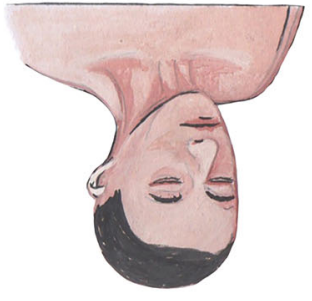

Step 1

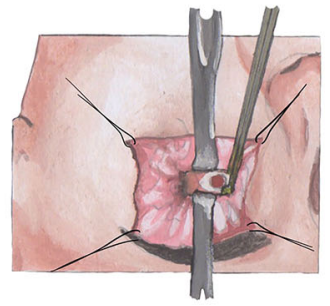

Step 5

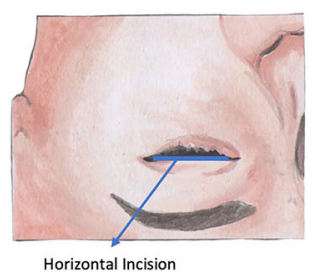

Step 2

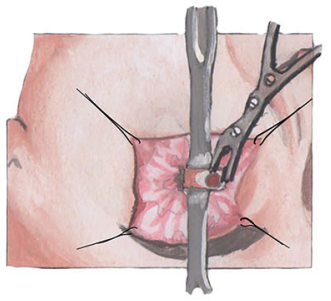

Step 6

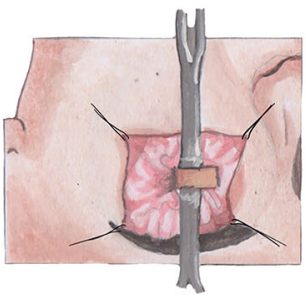

Step 3

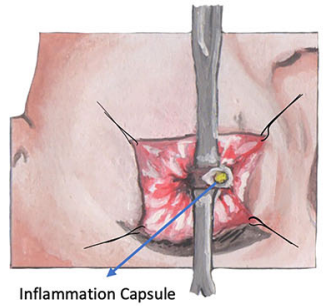

Step 7

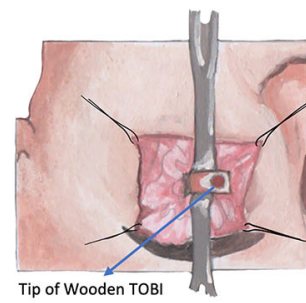

Step 4

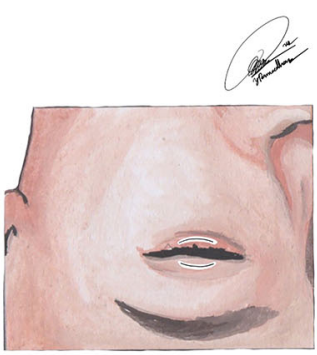

Step 8

Figure 3. Surgical step during the extraction of the wooden foreign body. 


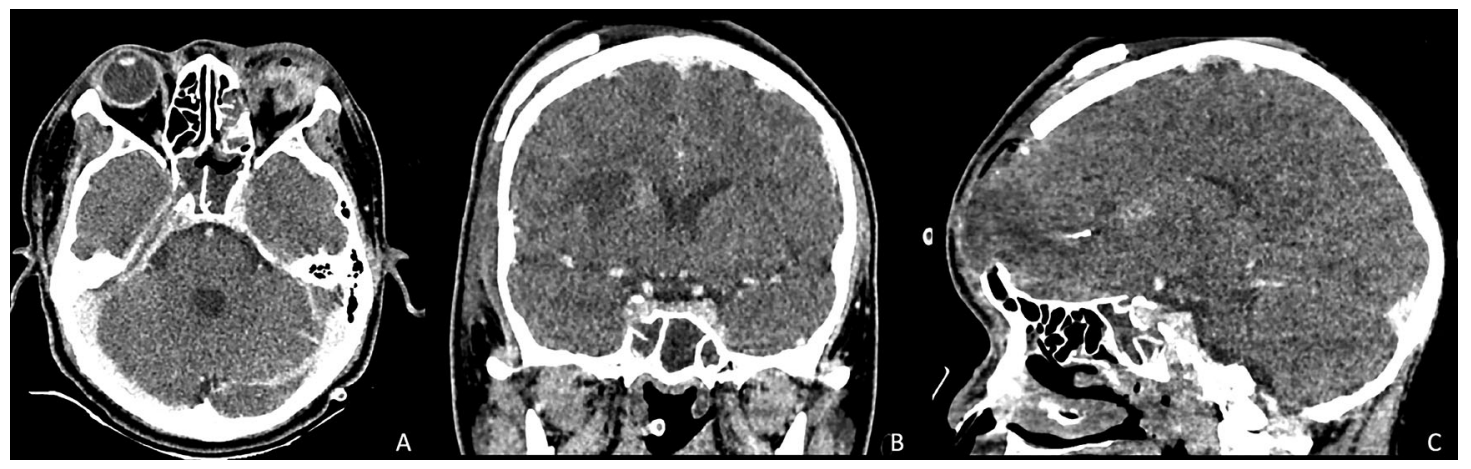

Figure 4. Non-contrast head computed tomography (CT) scan showed that the wooden foreign body was removed without any haemorrhage lesion.

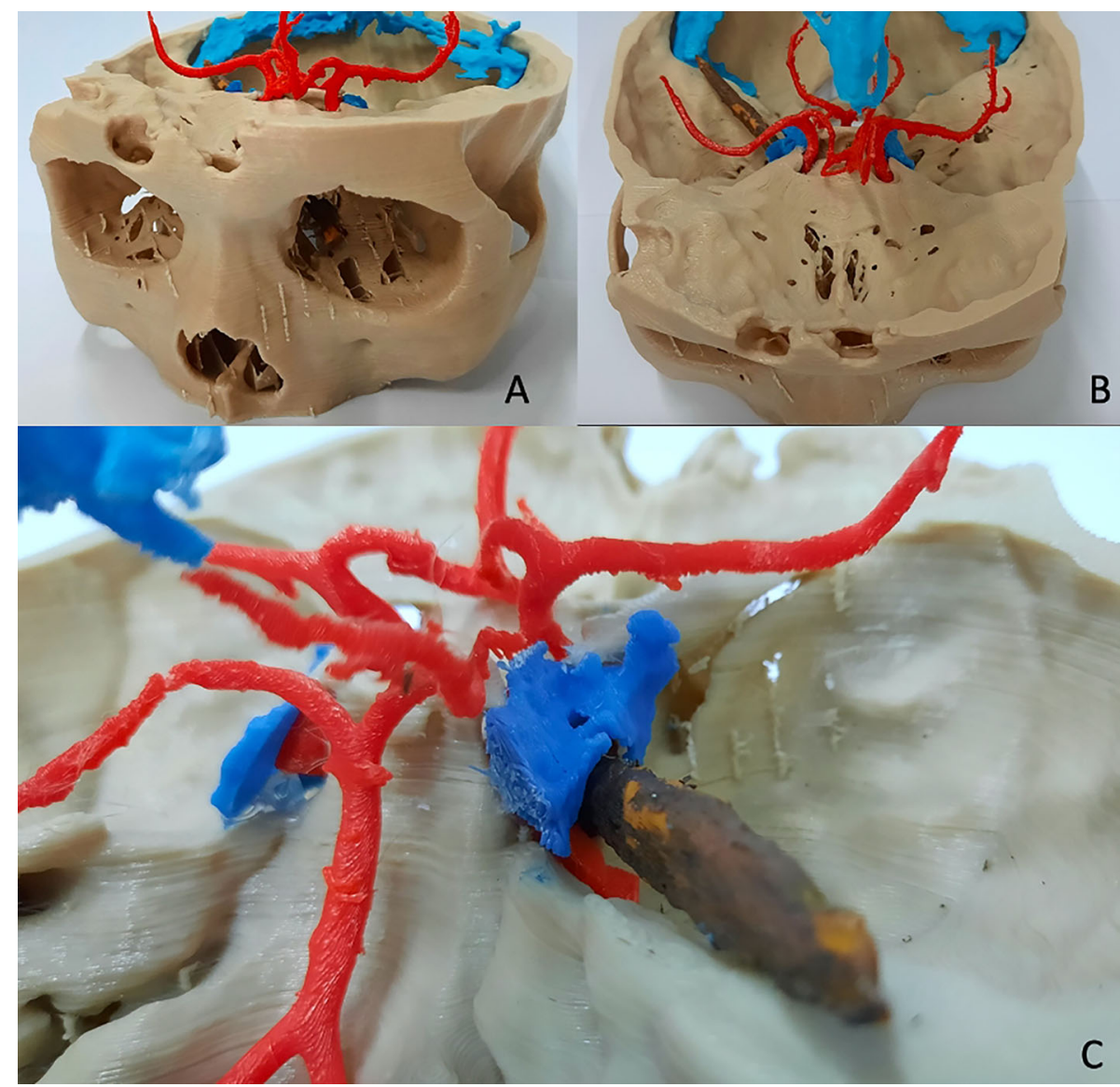

Figure 5. 3D-printed model reconstruction used for preoperative planning. (A). Tip of the wooden foreign body at the medial orbital wall. (B) and (C) Show that there is no lesion in the internal carotid artery (red) and cavernous sinus (dark blue).

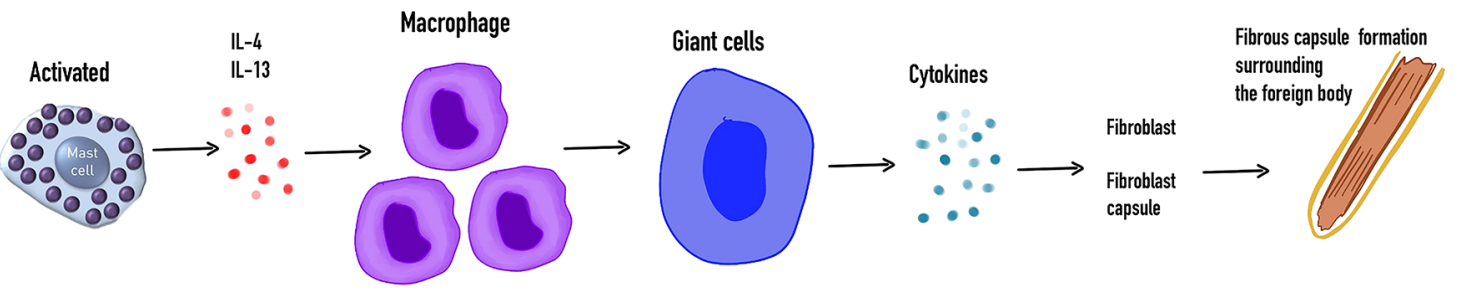

Figure 6. Illustration of the inflammatory and immune response to the foreign body on day 14. 
Based on details obtained from CT angiography (CTA), magnetic resonance venography (MRV), MRA, and the 3D-printed reconstruction, no serious neurovascular lesions were seen. Therefore, we decided to perform the second stage of surgery in the orbito-temporal part of the base of the skull base. The patient was positioned supine facing to the right for a transorbital approach, perpendicular to the wooden foreign body's entry zone. The eyelid was retracted gently, and the flap was sutured using silk 3.0. The conjunctiva was incised horizontally from the medial to the lateral canthus. We performed soft-tissue exploration of the orbit using a Langenbeck retractor until the medial wall of the orbit (ethmoid bone) was visible. When performing soft tissue retraction of the orbit using a Langenbeck retractor, it is essential to pay attention to the presence of an oculocardiac reflex due to stretching of the afferent stretch receptors that are transmitted through the ciliary nerve, Gasserian ganglion, and efferent vagal fibres, which are capable of increasing the parasympathetic tone. This could cause bradycardia in the patient.

After exploring the soft tissue of the orbit medially, the superficial tip of the wood was revealed in line with its trajectory. Osteotomy of the interlocking bone around the tip of the wooden foreign body was performed using a Kerrison punch, then the bone around the tip of the wood was meticulously removed. The wooden foreign body was gently extracted, perpendicular to the operator's view, using a bone rongeur. There was no brisk bleeding from the internal carotid artery nor from the cavernous sinus. Adequate debridement (irrigation for dilution) and haemostasis (using Gelfoam and Surgicel) were achieved after the wood was extracted. The wooden foreign body and the fibrous capsule formed were examined for infection via microbiological culture and antibiotic susceptibility testing. Finally, we sutured the skin in layers and performed tarsorrhaphy. The wood was most probably contaminated; therefore, we debrided any easily accessible impacted bone and other extracranial tissues along the track.

Regarding the timing of surgery, for our patient surgery was performed 14 days after the accident. The purpose of this was to ensure that a consistently thick fibrous capsule had formed over the entire body of the wood. This is a physiological foreign body reaction that protected the brain from the rough surface of the wood. Ibrahim et al., in their experimental study in 2017, reported that the immune response to foreign body implantation began on day 14. ${ }^{14}$ Mast cells (MC) are mobilized to the site of the wound, where they mature and are activated early in the inflammatory process through chemotactic inflammatory signaling. The activated MC secrete mediators, such as IL-4 and IL-13, attracting macrophages through chemotactic signals. To improve their effectiveness, macrophages fuse to form foreign body massive cells that reside at the tissue interface. ${ }^{15}$ Foreign-body giant cells are still incapable of digesting large implants but can secrete cytokines that cause fibroblasts to produce a collagen capsule that embraces the foreign body, and this effectively isolates it from surrounding tissue. ${ }^{16}$ On day 14 , the thickest fibrous capsule forms, followed by those on days 60,90 , and 180 (Figure 6). ${ }^{14}$ Therefore, watchful waiting until day 14 needs to be considered for a hemodynamically stable patient without severe neurovascular complication. Allograft cranioplasty was performed six months after the accident. This was done to reduce the risk of infection.

\section{Conclusion}

Many surgical approaches exist for managing transorbital PBIs. In this case, we decided to perform transorbital approach techniques perpendicular to the entry zone, 14 days after the injury. This enabled us to perform a minimally invasive procedure based on the patient's clinical and radiological features.

\section{Data availability}

All data underlying the results are available as part of the article and no additional source data are required.

\section{Acknowledgments}

The authors would like to thank all those who contributed to the process and completion of this report, including all neurosurgery consultant and fellow residents of the Department of Neurosurgery, Faculty of Medicine, Universitas Airlangga, Surabaya.

\section{References}

1. Turbin RE, Levin F, Maxwell DN: Recognition of transorbital intracranial injury. Clin. Ophthalmol. (Auckland, N.Z.). 2007; 1(1): 85-89.

2. Luerssen TG, Klauber MR, Marshall LF: Outcome from head injury related to patient's age. A longitudinal prospective study of adult and pediatric head injury.J. Neurosurg. 1988; 68(3): 409-416. PubMed Abstract | Publisher Full Text
3. Rootman J: Disease of orbit: a multidisciplinary approach. Philadelphia: Lippincot Willian \& Wilkins; 1st ed. 1988.

4. $\mathrm{Xu} \mathrm{L}$, et al.: The Surgical Strategies and Techniques of Transorbital Nonmissile Brain Injury. World Neurosurg. 2020; 144 e856-e865.

PubMed Abstract | Publisher Full Text 
5. Vakil MT, Singh AK: A review of penetrating brain trauma: epidemiology, pathophysiology, imaging assessment, complications, and treatment. Emerg. Radiol. 2017; 24(3): 301-309. PubMed Abstract | Publisher Full Text

6. Asadullah, Apriawan T, Bajamal AH, et al.: Management of penetrating brain injury: A case report. Indones. J. Neurosurg. 2020; 3(3): 74-79. Publisher Full Text

7. Schreckinger $M$, et al.: Transorbital penetrating injury: case series, review of the literature, and proposed management algorithm. J. Neurosurg. 2011; 114(1): 53-61. PubMed Abstract | Publisher Full Text

8. $\mathrm{Xu} \mathrm{F}$, et al.: The surgical management of a penetrating orbitocranial injury with a Bakelite foreign body reaching the brain stem. Brain Inj. 2013; 27(7-8): 951-956. PubMed Abstract | Publisher Full Text

9. Borkar SA, et al.: Transorbital penetrating cerebral injury caused by a wooden stick: Surgical nuances for removal of a foreign body lodged in cavernous sinus. Childs Nerv. Syst. 2014; 30(8): $1441-1444$.

PubMed Abstract | Publisher Full Text

10. Mzimbiri JM, et al.: Orbitocranial Low-Velocity Penetrating Injury: A Personal Experience, Case Series, Review of the literature, and Proposed Management Plan. World Neurosurg. 2016; 87: 26-34. PubMed Abstract | Publisher Full Text
11. Sun G, et al.: Management Strategy of a Transorbital Penetrating Pontine Injury by a Wooden Chopstick. World Neurosurg. 2016; 95: 622.e7-622.e15.

Publisher Full Text

12. Tabibkhooei A, Aslaninia A, Anousha K: Childhood Transorbital Skull Base Penetrating Injury: Report of 2 Cases and Review of Literature. World Neurosurg. 2019; 131: 213-216. PubMed Abstract | Publisher Full Text

13. Apriawan $\mathrm{T}$, Bajamal AH, Hermawan $\mathrm{Y}$, et al.: Three-dimensional (3D)-printed model reconstruction in pre-operative planning for wooden penetrating brain injury. Bioprinting. Elsevier B.V. 2021; 24(April): e00168. Publisher Full Text

14. Ibrahim $\mathrm{M}$, et al.: Characterization of the foreign body response to common surgical biomaterials in a murine model. Eur. J. Plast. Surg. 2017; 40(5): 383-392. PubMed Abstract | Publisher Full Text | Free Full Text

15. Nichols SP, et al.: The effect of nitric oxide surface flux on the foreign body response to subcutaneous implants. Biomaterials. 2012; 33(27): 6305-6312.

PubMed Abstract | Publisher Full Text | Free Full Text

16. Anderson JM, Rodriguez A, Chang DT: Foreign body reaction to biomaterials. Semin. Immunol. 2008; 20(2): 86-100. PubMed Abstract | Publisher Full Text | Free Full Text 


\section{Open Peer Review}

\section{Current Peer Review Status: ? ?}

\section{Version 1}

Reviewer Report 12 December 2022

https://doi.org/10.5256/f1000research.78129.r156737

(C) 2022 Choi C. This is an open access peer review report distributed under the terms of the Creative Commons Attribution License, which permits unrestricted use, distribution, and reproduction in any medium, provided the original work is properly cited.

\section{Chi Hoon Choi}

Chungbuk National University Hospital, Cheongju, South Korea

The authors describe a very rare case and its transorbital approach treatment.

This article is important in clinical practice showing the diagnostic images and surgical approach.

Strength: A very rare case

Weakness: It seems necessary to summarize in order according to the flow of time rather than an additional explanation.

Title: -

Abstract: -

Background and importance: -

Clinical presentation/ Surgical procedure/ Postoperative FU:

Combining the table and figure 3 would be better.

\section{Discussion:}

1. I would like to divide the paragraphs and categorize them into subheadings.

2. Figure 5: It would be helpful to describe the details of the preoperative plan by $3 \mathrm{~d}$ printing (the specifications of the printer \& ink and the simple usage environment).

3. Figure 6: It is thought to be an inadequate picture to convey the author's intention. It can be omitted and would be better to present pathological pictures of the foreign body or clinical data of patients.

Is the background of the case's history and progression described in sufficient detail? Yes

Are enough details provided of any physical examination and diagnostic tests, treatment given and outcomes? 
Yes

Is sufficient discussion included of the importance of the findings and their relevance to future understanding of disease processes, diagnosis or treatment?

Yes

Is the case presented with sufficient detail to be useful for other practitioners?

Yes

Competing Interests: No competing interests were disclosed.

Reviewer Expertise: Neroradiology \& Neurointervention

I confirm that I have read this submission and believe that I have an appropriate level of expertise to confirm that it is of an acceptable scientific standard, however I have significant reservations, as outlined above.

Reviewer Report 30 September 2022

https://doi.org/10.5256/f1000research.78129.r150802

(C) 2022 Murakami M. This is an open access peer review report distributed under the terms of the Creative Commons Attribution License, which permits unrestricted use, distribution, and reproduction in any medium, provided the original work is properly cited.

Mamoru Murakami

Kyoto Tanabe Central Hospital, Kyoto, Japan

\section{Comments to the author}

Title: Transorbital approach for the management of an orbito-temporal penetrating brain injury (skull base region) secondary to wooden spikes.

The authors describe a very rare case of penetrating injury, treated well via transorbital approach. The article is well written. They provide suggestions about the surgical approach and the timing of surgery, which are important in clinical practice.

\section{Title and abstract:}

The title is appropriate for the content of the article. The abstract is concise and accurately summarises the essential information of the paper, although it would be better if authors included the comment about the timing of the surgery in conclusion.

Case report:

The clinical case presentation is well written but some minor points that should be clarified:

1. There is no comment about a conventional angiography. The wooden spike penetrated near the cavernous sinus. In case of suspicion for the injury of internal carotid artery, there are opinions that digital subtraction angiogram (DSA) should be performed to evaluate the 
lesion which 3DCTA could not clearly demonstrate, such as arterio-venous fistula (AVF). If you did not perform DSA in this case, could you explain that reason?

2. The timing of the second surgery is very important. If the foreign body is wooden, serious infection is often problematic, since the porous nature of wood is a strong growth medium for microorganisms. During waiting for 14 days to the second surgery, there might be possibility of exacerbation of epidural or subdural abscess. Some neurosurgeons might insist the early second-surgery to prevent the serious infections. In case of penetrating brain injury of wooden spikes, do you consistently recommend waiting until 14 days, which the wooden spikes form the fibrous capsule?

Is the background of the case's history and progression described in sufficient detail? Yes

Are enough details provided of any physical examination and diagnostic tests, treatment given and outcomes?

Yes

Is sufficient discussion included of the importance of the findings and their relevance to future understanding of disease processes, diagnosis or treatment?

Partly

Is the case presented with sufficient detail to be useful for other practitioners?

Yes

Competing Interests: No competing interests were disclosed.

Reviewer Expertise: neurosurgery

I confirm that I have read this submission and believe that I have an appropriate level of expertise to confirm that it is of an acceptable scientific standard, however I have significant reservations, as outlined above. 
The benefits of publishing with F1000Research:

- Your article is published within days, with no editorial bias

- You can publish traditional articles, null/negative results, case reports, data notes and more

- The peer review process is transparent and collaborative

- Your article is indexed in PubMed after passing peer review

- Dedicated customer support at every stage

For pre-submission enquiries, contact research@f1000.com 